\title{
Experimental Investigation of the Periodic Unsteady Transonic Flow Field Around a Compressor Blade by Means of Particle Image Velocimetry (PIV)
}

\author{
A. Lehr \\ TRUMPF Maschinen AG, Baar, Switzerland
}

A. Bölcs

Swiss Federal Institute of Technology, Lausanne, Switzerland

In the present article, a study of the time-dependent transonic flow field around an isolated airfoil in a Laval nozzle is presented. In order to obtain instantaneous flow field information all over the flow around the blade, the Particle Image Velocimetry (PIV) method has been employed allowing one to obtain velocity data in an illuminated light sheet with a high data acquisition rate and high spatial resolution. From these instantaneous PIV measurements the mean velocity field and turbulence quantities of the flow easily can be obtained by statistical means.

A single compressor blade with a NACA 3506 profile and a chord length of $78 \mathrm{~mm}$ is centrally mounted in the test section. A vibration system driven by a hydraulic motor is externally attached to the blade. The rotational motion of the motor is translated to a plunging blade vibration perpendicular to the chord via an eccentric shaft and connecting arm. The vibration frequency can be varied between 0 and $100 \mathrm{~Hz}$, and the average amplitude is approximately $0.4 \mathrm{~mm}$. The entire blade-motor assembly is mounted to the tunnel sidewall via a circular disc to allow easy adjustment of the inlet flow incidence angle. The exit pressure of the nozzle can be varied by a rotating flat plate $(15 \mathrm{~mm}$ high, $39 \mathrm{~mm}$ wide, and $2 \mathrm{~mm}$ thick) that is mounted approximately 5 times the chord length downstream of the blade mid-chord. The rota-

Received 25 June 2002; accepted 1 July 2002.

This work is supported by the Ecole Polytechnique Fédérale de Lausanne and the Leonhard Euler Centre, Swiss ERCOFTAC Pilot Centre. The authors wish to express their appreciation for permission to publish these results.

Address correspondence to A. Lehr, MTS Machinery Tools \& Services AG, Willikonerstr. P.O. Box, Oetwil am See, CH-8618, Switzerland. E-mail: a-lehr@mtstechniques.ch tional frequency of this assembly can be varied between 0 and $100 \mathrm{~Hz}$, producing upstream-running waves at the doubled frequency (i.e., 0 to $200 \mathrm{~Hz}$ ). The above excitation systems can be precisely synchronized and the phase lag between them can be freely varied. This allows for unsteady measurements to be conducted in the presence of only the downstream perturbation, only the blade vibration, or a combination of the two for different phase angles.

For the first test series the existing PIV measurement system at Turbomachinery Institute (LTT) has been applied to measure the transonic steady flow field around the compressor blade. In another test series, measurements of the timedependent periodic flow field were conducted by means of PIV. This measurement series consisted of three subtasks: the measurement of the unsteady flow field with only back pressure variation, with only blade vibration, and finally with a combination of both back pressure variation and blade vibration. These results quantify not only the unsteady motion of the normal shock for each case on the suction side of the blade, but also give a detailed insight into the instantaneous transonic flow field around the compressor blade. Furthermore, the results of the set of unsteady measurements with both back pressure variation and blade vibration (3) is compared with the combination of the results of the sets of unsteady measurements of only back pressure variation (1) and only blade vibration (2) to validate the superposition principle.

Finally, phase averaging of the instantaneous flow quantities produced a large database for statistical treatment (e.g., turbulence) and thus the ability to compare the averaged results with those from traditional measurement techniques.

Keywords Aeroelasticity, Forced response, Unsteady flow field, Field measuring method, Particle Image Velocimetry (PIV), Transonic flow, Turbomachinery 


\section{INTRODUCTION}

Present research work at the LTT focuses on the effects of flutter in turbomachinery. Under certain conditions, a blade row operating in a uniform flow field can enter a self-excited oscillation known as flutter. The blade motion is sustained by the extraction of energy from the uniform flow during each vibratory cycle, with the flutter frequency corresponding generally to one of the lower blade or coupled blade-disk natural frequencies. The outstanding feature of flutter is that it leads to rapidly increasing blade vibrations, which can destroy the engine (Fleeter and Jay, 1987).

Very often the aerodynamic phenomenon of flutter is simulated by means of artificially created forced vibration of the blades. In these vibration systems the mode, frequency, and amplitude of vibration easily can be controlled, so that the flutter conditions safely can be simulated in an experiment.

The forced response problem encompasses potential flow interactions between fixed and rotating blade rows, as well as periodic impingement of upstream-generated wakes or shocks on downstream blading. These forced response phenomena remain a primary concern in gas turbine engine design and have important implications for engine life and reliability. In cases where the frequency of the aerodynamic forcing function matches the eigenfrequency of the blade structure, significant vibrations can occur and lead to structural fatigue and eventual failure.

To date, a significant research effort has been devoted to the quantification of the unsteady blade loading induced by such aerodynamic disturbances. Combined with knowledge of the structural characteristics of the blade assembly, this information can be used to predict blade vibration amplitudes and ultimately to determine the susceptibility of the blade to forced response phenomena. In order to avoid failure of the turbine components and to increase the efficiency of the turbomachine, a better understanding of the flutter phenomenon is required.

For the measurement of these unsteady flows single point techniques usually are used. These techniques measure the unsteady flow fluctuations of pressure and velocity pointwise on surfaces (pressure transducers, hot-film, etc.) or in the flow field (LDA, L2F, hotwire probes, etc.). However, these measurement techniques cannot directly provide information over the entire instantaneous flow field and therefore cannot reveal flow structures in unsteady flows.

One measurement technique that is able to provide instantaneous flow field data and reveals flow structures in unsteady flows is the PIV method (Adrian, 1991; Liu et al., 1991; Willert et al., 1995). The PIV technique yields good results for the investigation of transonic and supersonic flows (Bryanston-Cross, 1995; Bryanston-Cross et al., 1991; Höcker, 1990; Kompenhans and Höcker, 1988; Towers et al., 1991). Previously published applications of the PIV method to turbine-like flow problems include external blade cooling (Langowski and Voigt, 1994) or "Dynamic stall in a pitching-mode of a wing" (Kompenhans et al., 1994; Wernert et al., 1995). A good selection of PIV pa- pers can be found in Grant (1994). Visser and Jonker (1995) investigated the 3-D flow field of a radial pump impeller. Grant et al. (1994) and Tisserant and Breugelmans (1995) applied the PIV method to the investigation of rotor-stator interaction in turbomachines.

The ability of PIV to measure the instantaneous flow field around the blade makes it an ideal technique to investigate blade vibration and forced response phenomena. To the knowledge of the authors this is the first application of the PIV method to the investigation of the forced-response problem in turbomachinery.

For the investigation of blade vibration and forced response phenomena it seems promising to use the PIV measuring technique, since this technique can measure the instantaneous full flow field around the blade.

\section{EXPERIMENTAL SETUP}

\section{Test Facility}

The experimental measurements were conducted in the Unsteady Transonic Wind Tunnel (Figure 1) at the Ecole Polytechnique Fédérale de Lausanne. Air is supplied to this open cycle facility on a continuous basis by a 4-stage centrifugal compressor with a pressure ratio of 3.5 and maximum flow rate of $10 \mathrm{~kg} / \mathrm{s}$. The air enters the tunnel through an inlet settling chamber and is accelerated by a converging nozzle into a rectangular test section measuring $200 \mathrm{~mm}$ (height) by $40 \mathrm{~mm}$ (width). The air exiting the test section is vented through a downstream valve to the atmosphere.

A single compressor blade with a NACA 3506 profile and a chord length of $78 \mathrm{~mm}$ is centrally mounted in the test section. The blade is made of Plexiglas to allow the light sheet to pass through the blade in order to minimize reflections in the test section and to enable measurements on both sides of the blade. A vibration system driven by a hydraulic motor is externally attached to the blade (Figure 2).

The rotational motion of the motor is translated to a periodically varying linear motion of the blade perpendicular to the chord via an eccentric shaft and connecting arm. The vibration frequency can be varied between 0 and $100 \mathrm{~Hz}$, and the average amplitude is approximately $0.4 \mathrm{~mm}$. The entire blade-motor assembly is mounted to the tunnel sidewall via a circular disc to allow easy adjustment of the inlet flow incidence angle. Within this disk, the blade entry passage is equipped with a specially designed labyrinth sealing system, which is described in further detail by Bölcs and Norryd (1994). This system significantly reduces the effects of flow leakage on the steady and unsteady measurements while still ensuring an unrestricted motion of the blade.

Approximately $375 \mathrm{~mm}$ downstream of the blade mid-chord, a small flat plate ( $15 \mathrm{~mm}$ high, $39 \mathrm{~mm}$ wide, and $2 \mathrm{~mm}$ thick) is mounted within the rotating shaft of a second hydraulic motor (Figure 3). The rotational frequency of this assembly can be varied between 0 and $100 \mathrm{~Hz}$, producing upstream-running waves at the doubled frequency (i.e., 0 to $200 \mathrm{~Hz}$ ). 


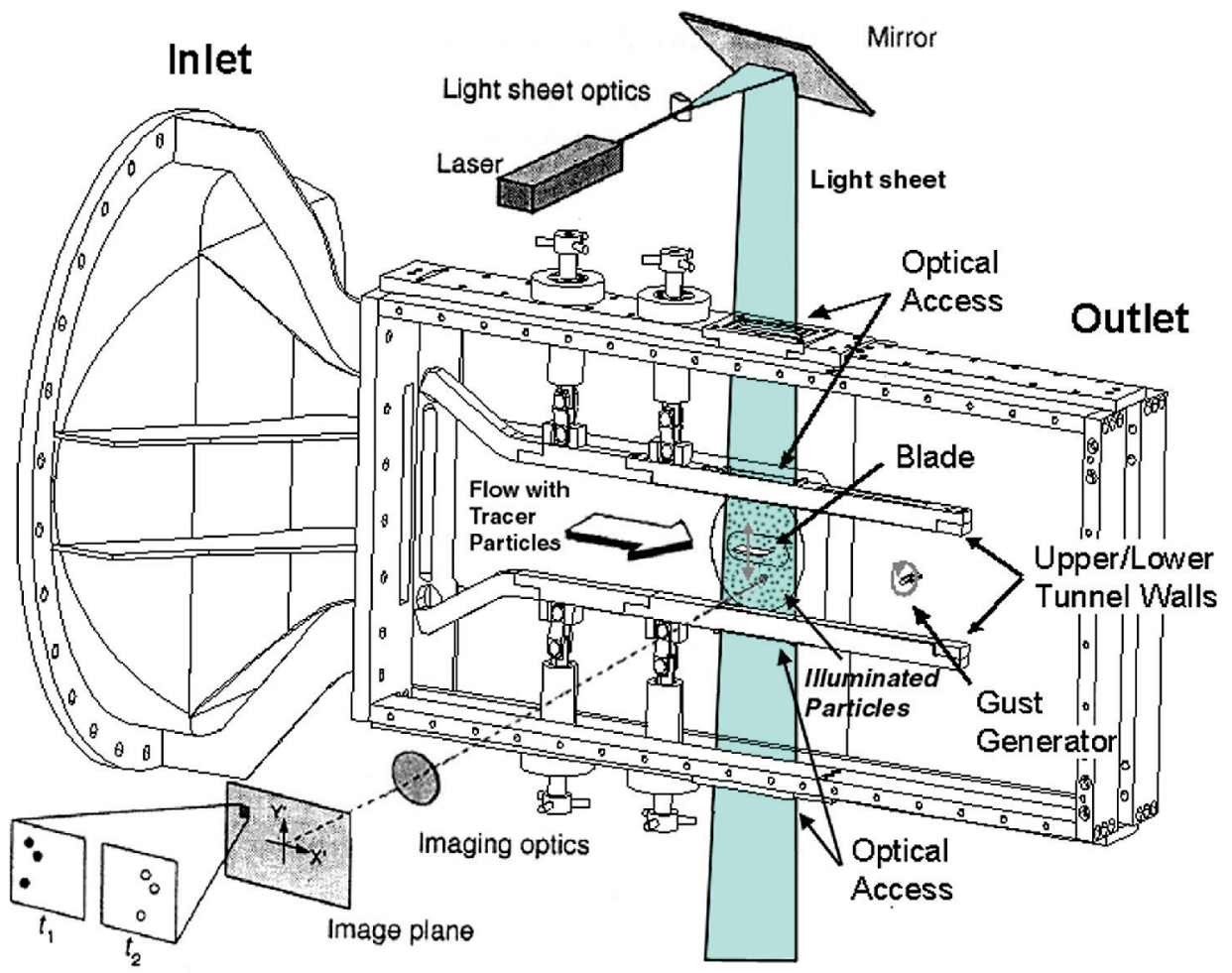

- First light pulse at $\mathrm{t}_{1}$

- Second light pulse at $t_{2}$

\section{Test Section}

FIGURE 1

The Unsteady Transonic Wind Tunnel.

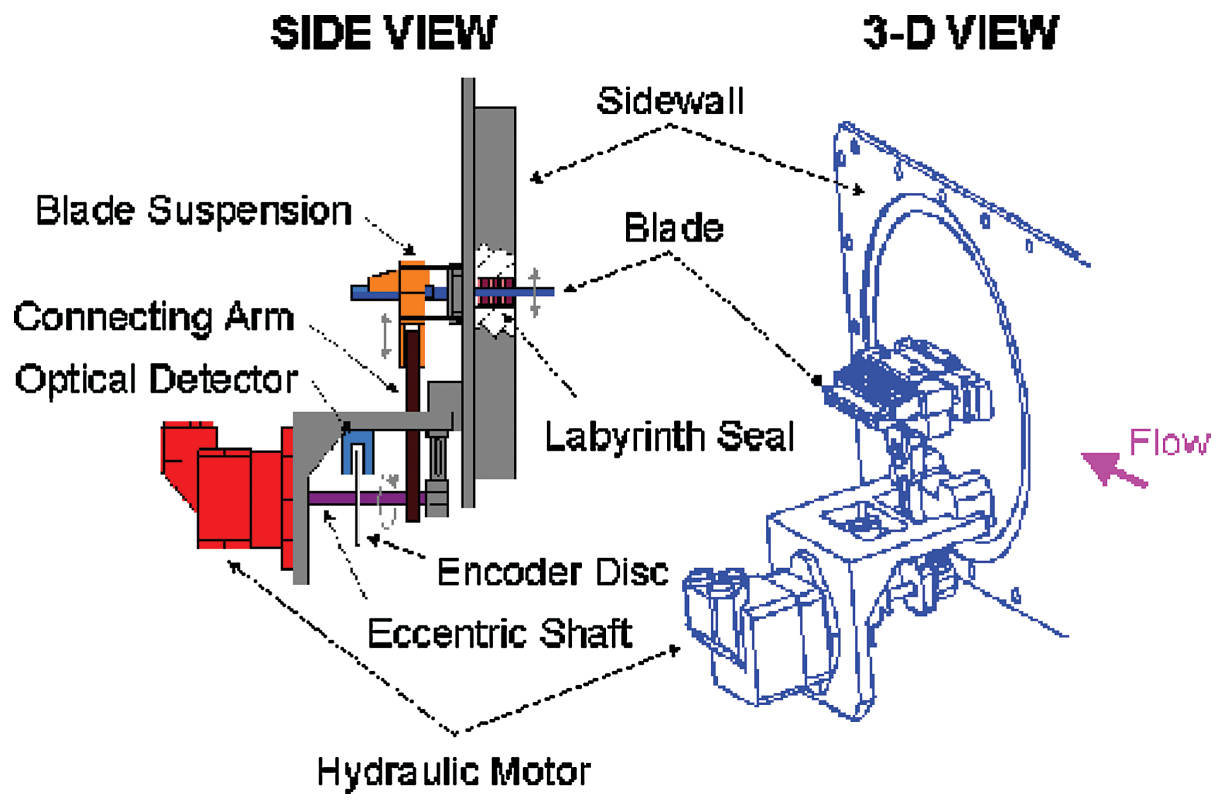

FIGURE 2

Vibration system. 


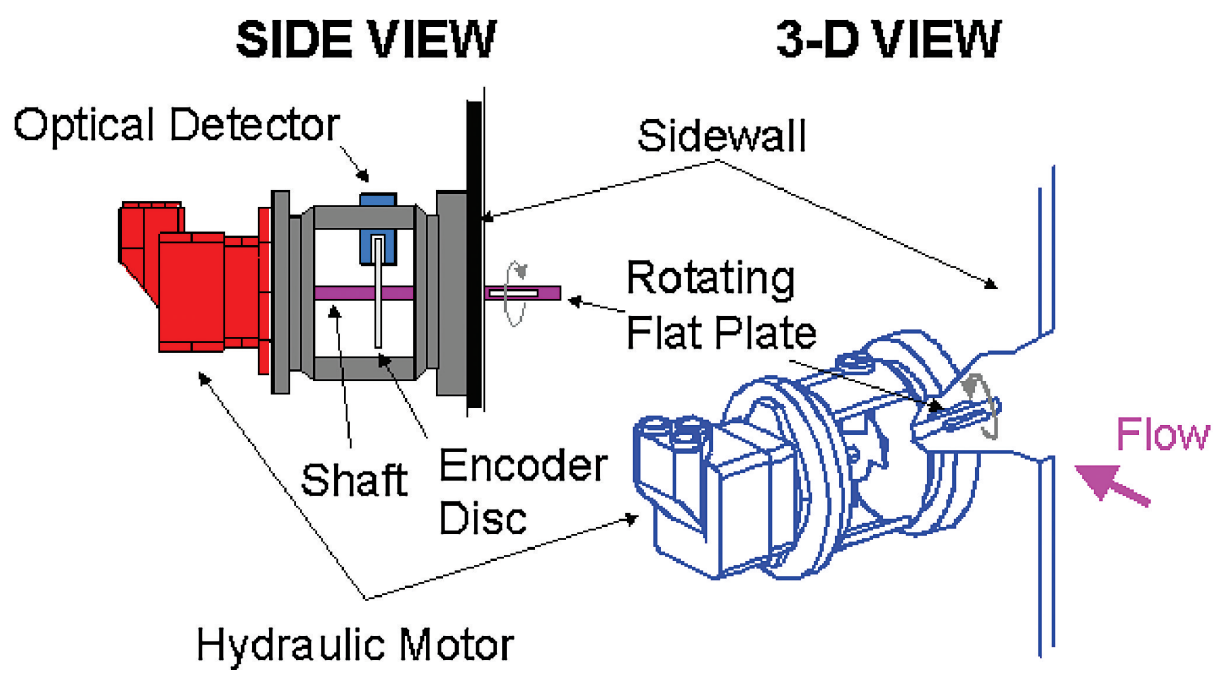

FIGURE 3

Gust generator.

The above excitation systems can be precisely synchronized and the phase lag between them can be freely varied. This allows unsteady measurements to be conducted in the presence of only the downstream perturbation, only the blade vibration, or a combination of the two for different phase angles.

\section{The PIV System}

The laser used for the experiments is a Quantel TwinsB NdYag high-energy double oscillator pulsed laser. The time delay between a pair of pulses can be adjusted from 1 microsecond to 1 second. The laser provides light pulses with a maximum energy of $320 \mathrm{~mJ}$ at a wavelength of $532 \mathrm{~nm}$.

The pulse duration is approximately $5 \mathrm{~ns}$ with a peak power of $64 \mathrm{MW}$. A plano-concave lens ( $-30 \mathrm{~mm}$ focal length) combined with two plano-cylindrical lenses (76.2 and $300 \mathrm{~mm}$ focal length) transforms the laser beam into a thin vertical light sheet. By adjusting the distance between these lenses, the desired thickness and width of the light sheet can be obtained. All lenses have an anti-reflecting coating.

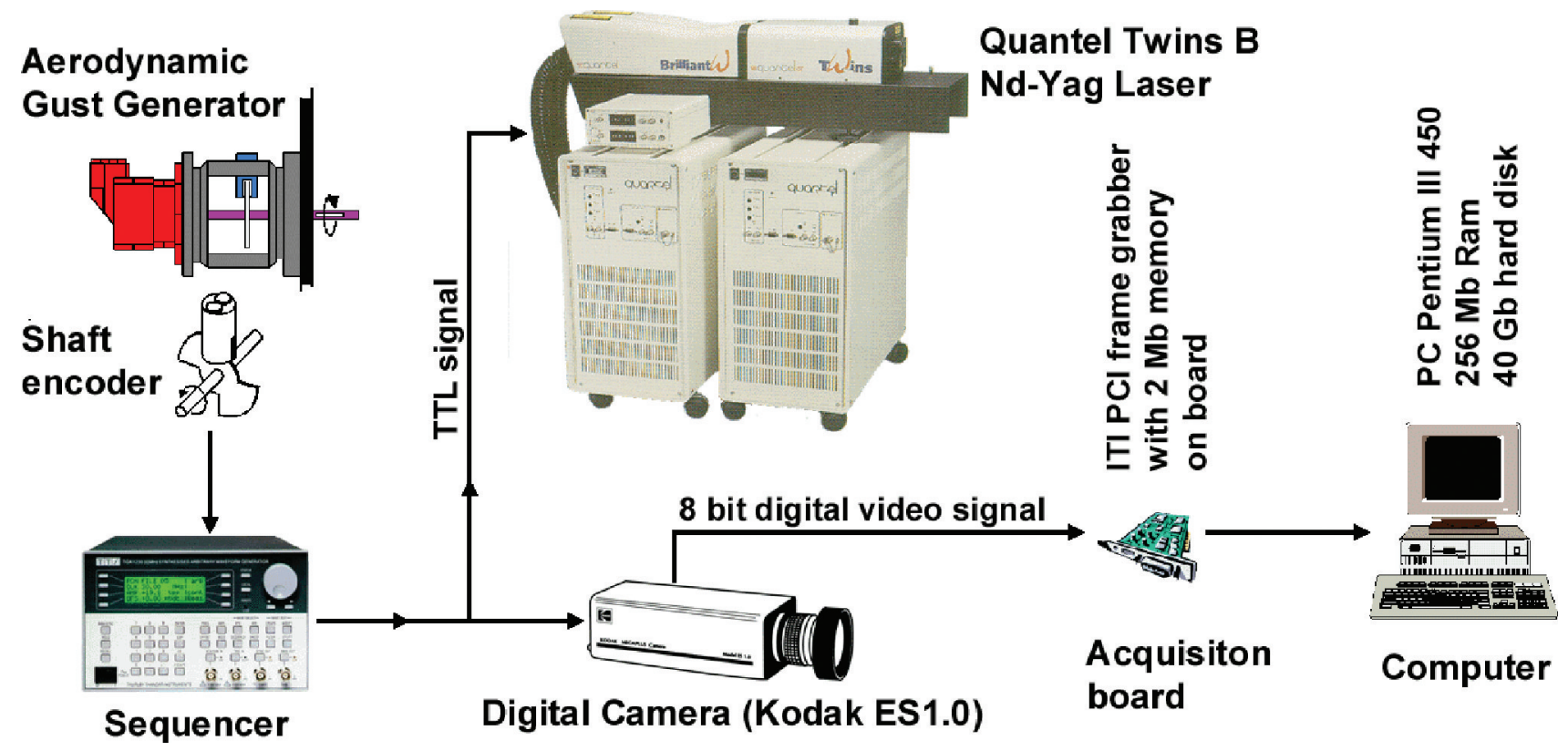

FIGURE 4

Data acquisition system. 


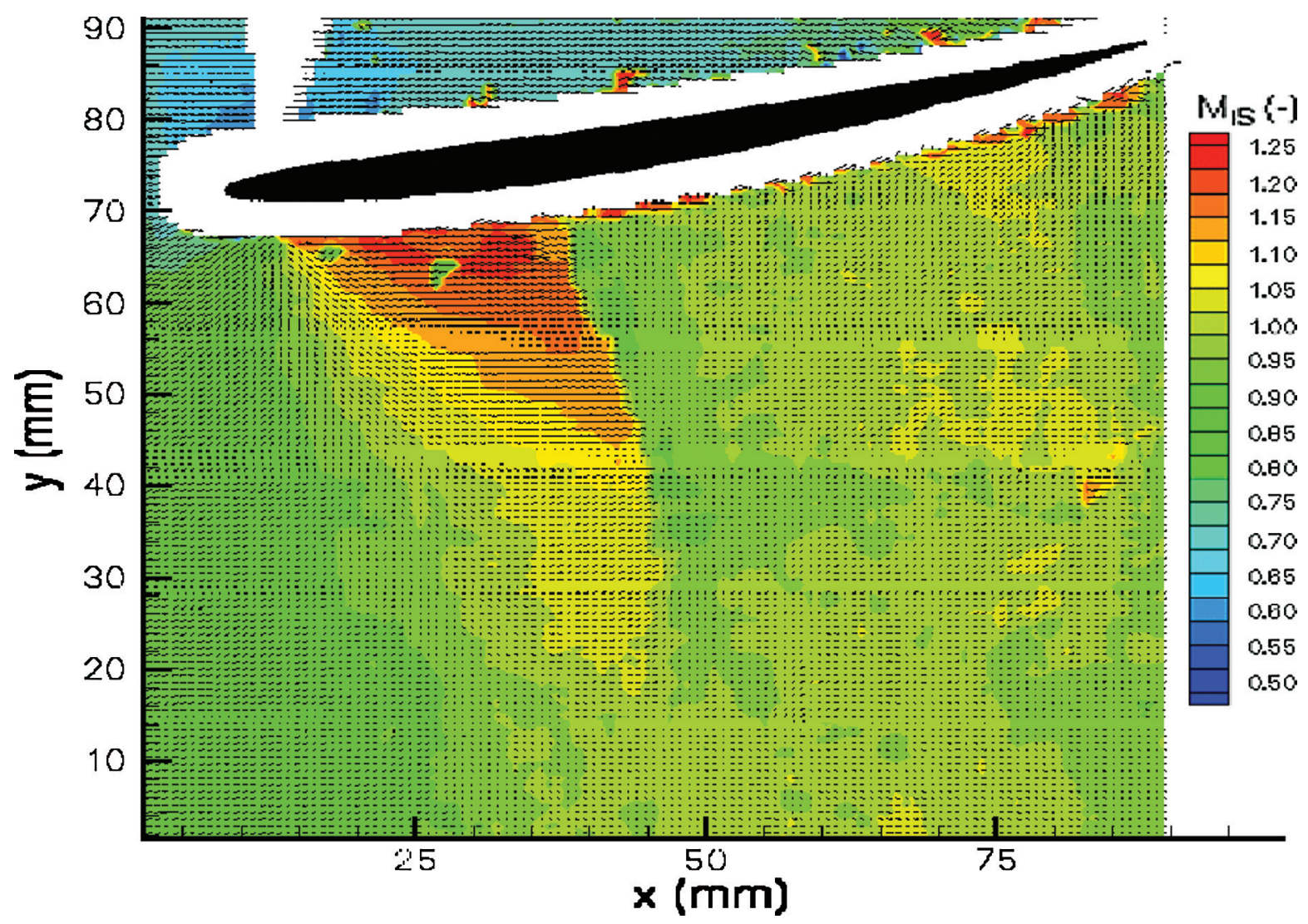

FIGURE 5

Instantaneous velocity disturbances $\mathrm{V}-\mathrm{V}_{\text {mean }}$ and isentropic Mach number field, $M_{\infty}=0.65, i=5^{\circ}$.

The light scattered by the particles is recorded perpendicular to the light sheet. For the recording of the scattered light a Kodak ES 1.0 camera is used. This camera has a CCD interline transfer sensor, which has a pixels array of $1008(\mathrm{H})$ by $1018(\mathrm{~V})$ pixels. Each pixel measures nine microns square with a $60 \%$ fill factor using a micro lens. The 8-bit digital output of the camera corresponds to a resolution of 256 gray levels. For PIV applications the camera is used in a special double exposure frame-triggering

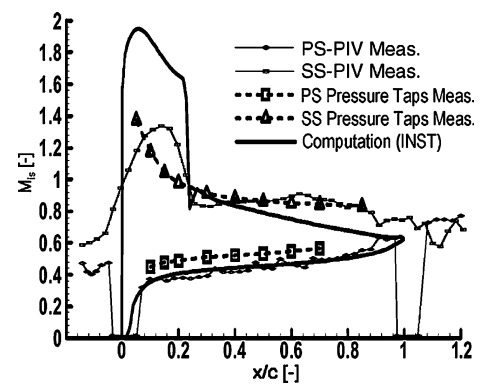

FIGURE 6

Isentropic Mach number distribution on streamlines close to the blade surface (approx. $5 \mathrm{~mm}$ ) for PIV measurements, on the blade surface for pressure taps measurements and calculation, $M_{\infty}=0.60$. mode. This mode allows the capture of 2 images separated by a delay ranging from $2 \mu \mathrm{sec}$ to $66 \mathrm{msec}$. A Nikkor $55 \mathrm{~mm}$ micro lens is mounted on the camera. The F-number is adjusted to 2.8. For a typical recording situation, the distance between the camera and the light sheet is approximately $70 \mathrm{~cm}$.

The complete system including laser, light sheet optics, and digital camera is mounted on a traversing system that allows easy adjustment of the light sheet to the position of interest.

\section{Data Acquisition and Processing}

Since the out-of-plane component of the flow in the Unsteady Transonic Wind Tunnel (Figure 1) is two orders of magnitude smaller than the in-plane component, a single camera PIV system was used instead of a stereoscopic PIV system.

Figure 4 shows the complete PIV data acquisition system that was assembled around the camera. The steady-state flow conditions are determined from the inlet plenum total pressure and temperature and static pressures measured along the test section sidewall axially upstream the compressor blade. For steady-state flow field measurements by means of PIV, the laser was triggered internally with a frequency of $10 \mathrm{~Hz}$. The digital camera and the frame grabber are synchronized on the double laser pulses. For unsteady measurements the laser is triggered on a selected phase 
angle of the vibrating blade and the rotating flat plate of the gust generator, respectively. For unsteady measurements with both blade vibration and gust perturbation, the laser and the vibrating blade are triggered on the position of the gust generator. To control the perturbation phase angle (PPA) between the phase angle of the gust generator and the vibrating blade, an in-house LabVIEW software interface is used. For the results shown in this article, the perturbation phase angle PPA was set to zero degrees.

The PIV image acquisition starts with a TTL signal from the laser in a steady-state case and a TTL signal from the shaft encoder in an unsteady case, respectively. Two images are captured in rapid succession. This is accomplished by capturing the first image in the photo diode array, transferring this image to the CCD array, and then capturing a second image in the photo diode array. The first image is transferred from the CCD array to the frame grabber while the second image is being captured by the photo diode array. The second image is then transferred into the CCD array and subsequently onto the frame grabber's second image buffer. The frame grabber is an Imaging Technology PCI frame grabber with $2 \mathrm{MB}$ memory onboard. The PC is equipped with $256 \mathrm{MB}$ RAM and $40 \mathrm{~GB}$ hard disk space. During the PIV measurement series, 50 image pairs are written in real time into the PC's RAM memory. Subsequently, the acquisition is stopped and the images are saved on the hard disk. The PIV recordings from the camera are interrogated with the
PIV software package VISIFLOW from AEA Technology. For the images, a cross-correlation analysis method is used with interrogation window sizes of $16 \times 16$ pixels and $32 \times 32$ pixels that correspond in the light-sheet to an area of approximately $0.5 \times 0.5 \mathrm{~mm}^{2}$ and $0.9 \times 0.9 \mathrm{~mm}^{2}$, respectively. The interrogation windows were overlapped by $50 \%$. Since the camera acquires images with a resolution of 1008 by 1018 pixels, each recording results in a $120 \times 120$ vector field of instantaneous velocity.

Due to the presence of reflections (blade, sidewall sealings, etc.), the data set usually contains a small number of spurious vectors $(<5 \%)$. The vector field is therefore validated with predefined thresholds for the vector continuity and velocity magnitude. Vectors that do not fall within the thresholds are removed and replaced by vectors with a lower correlation peak order. Due to the reflection problem, a systematic error in the calculation of the vectors may occur. These vectors are also detected and removed. A weighted average of surrounding vectors fill the remaining gaps (Lehr and Bölcs, 2000).

\section{Tracer Particles}

For high-speed PIV applications the generation of the particles is of the utmost importance. For all measurements presented in this article, a Laskin nozzle generator has been used to generate sufficiently small seeding particles, as solvent DEHS

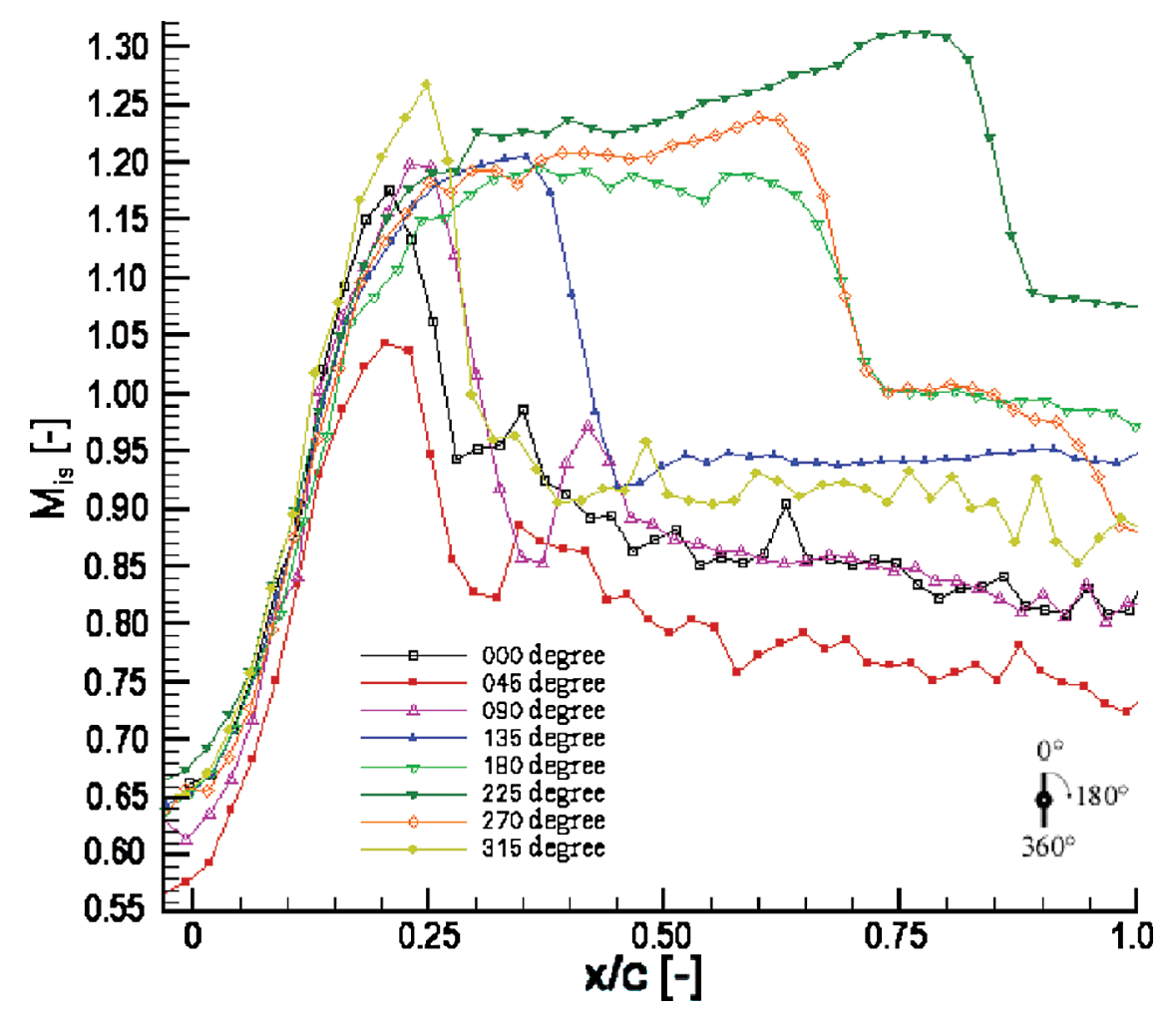

FIGURE 7

Isentropic Mach number distribution on the suction side with gust generation at different phase angles, $M_{\infty}=0.65, f=20 \mathrm{~Hz}$. 
(Di-Ethyl-Hexyl-Sebacat) has been employed. DEHS is a non soluble, colorless and odorless liquid that evaporates completely after long time. A droplet with a diameter of $0.3 \mu \mathrm{m}$ has a lifetime of approximately 4 hours. The generated particles are spherical with a diameter of about $1 \mu \mathrm{m}$. A particle size distribution of DEHS particles for the same conditions as used for all experiments presented in this article is given by Lehr and Bölcs (2000).

At a flow velocity of $300 \mathrm{~m} / \mathrm{s}$ for example, the particle images have moved approximately $1.6 \mu \mathrm{m}$ in the recording plane during the length of a single laser pulse (5 ns). This distance is much smaller than the diameter of the particle images. Thus, blurring of the particle images is avoided by the very short duration of the laser pulse. At the same flow velocity a time delay between the two laser pulses of $2.5 \mu \mathrm{sec}$ was used to obtain a sufficient displacement of approximately $240 \mu \mathrm{m}(\approx 12$ pixels $)$ between the two particle images in the recording plane. However, the density of particle images in the recording plane was high enough to find images of several particle pairs within the interrogation windows in most cases.

\section{MEASUREMENT PROGRAM AND FLOW CONDITION}

Due to the presence of significant boundary layers on the sidewalls of the test section (refer to Lehr and Bölcs (2000)), testing was conducted in the mid-span plane for a single flow incidence angle of $i=5^{\circ}$. Three different kinds of unsteady tests were performed: (1) with a fixed blade and pressure perturbations created by the gust generator, (2) with a vibrating blade and a fixed gust generator, and (3) with a superposition of (1) and (2). For steady-state measurements and measurements with only blade vibration the position of the flat plate of the gust generator was fixed at an angle of $\cos \varphi=0.5$, i.e., the average blockage of the rotating plate. Unsteady tests were performed at an excitation frequency of $f=20 \mathrm{~Hz}$. A wider range of

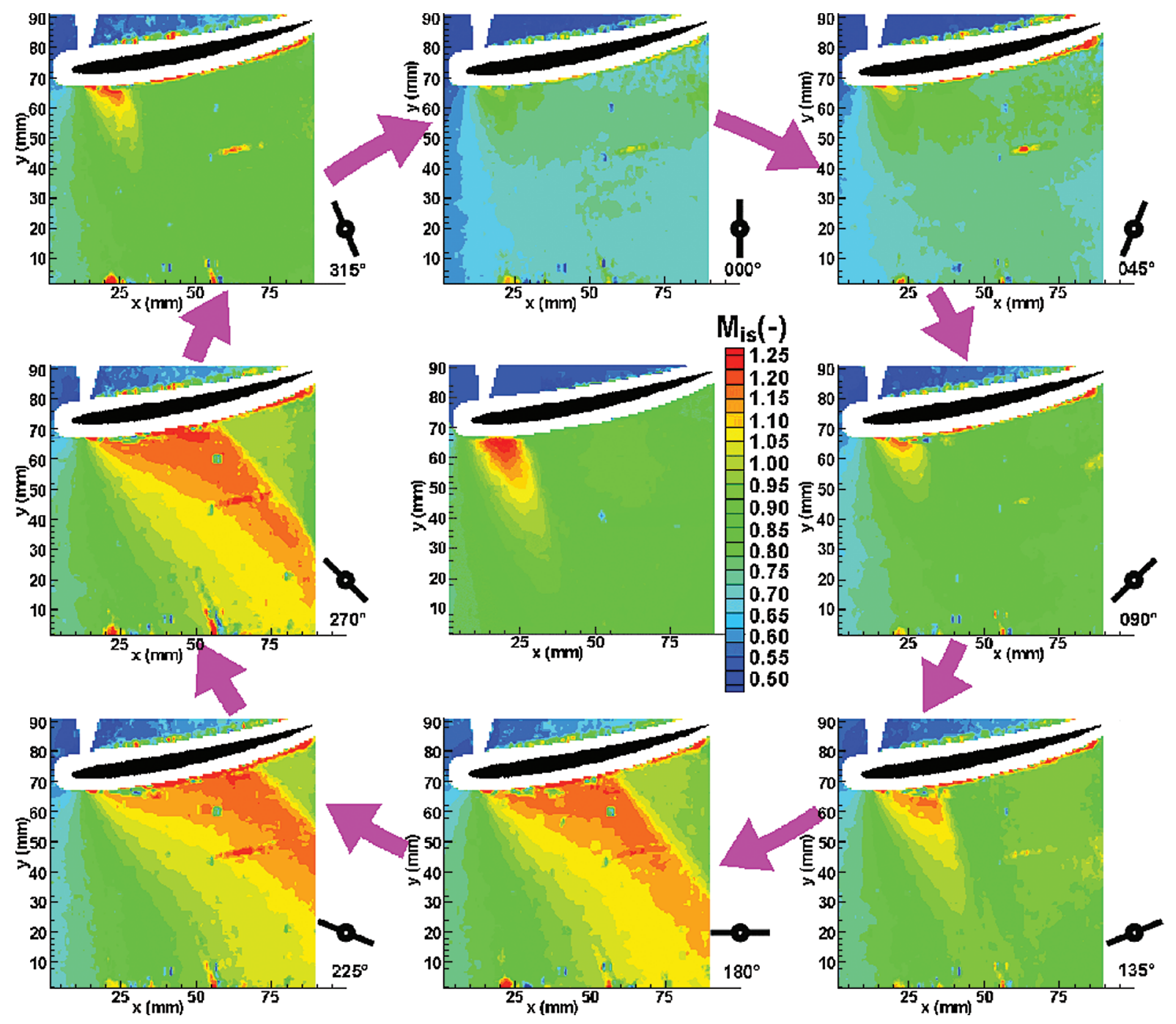

FIGURE 8

Time-variant flow field at different positions of the gust generator, $f=20 \mathrm{~Hz}$, steady-state flow field in the center, $M_{\infty}=0.65$. 
excitation frequencies is presented by Lehr and Bölcs (2000). For unsteady tests the measurement system was triggered on eight phase angles $0^{\circ}<\varphi<360^{\circ}$ that correspond to one excitation cycle. The perturbation phase angle PPA, i.e., the angle between the phase angle of the gust generator and of the vibrating blade, was set to zero degrees.

For all results shown in the present work, the Reynolds number based on the chord length and the inlet velocity was $\mathrm{Re}=$ $1.18 \times 10^{6}$. The inlet Mach number was fixed to $M_{\infty}=0.6$ and $M_{\infty}=0.65$, respectively. The inlet total temperature was set to $T_{T}=305 \mathrm{~K}$. These values were evaluated from static pressure measurements at the entrance of the test section, approximately two chord lengths upstream the leading edge of the blade, and total pressure and temperature measurements in the settling chamber, respectively.

\section{UNCERTAINTY}

For the estimation of the uncertainty of PIV velocity measurements many parameters have to be considered (Raffel et al., 1998). Systematic errors occur due to uncertainty in the determination of the geometrical parameters and fabrication tolerances of the camera devices and lenses. Non systematic errors are mainly due to uncertainty in the determination of the average particle displacement in the interrogation region. These depend on the size of the interrogation region, the time separation be- tween the laser pulses, the magnification of the recording, the out-of-plane velocity component, the turbulence and the length scale of the flow, etc. The choice of the recording and interrogation parameters is therefore of significant importance for accurate and reliable velocity measurements. As the flow in the test section is quasi two-dimensional, the out-of-plane component of the vectors causes only negligible errors.

An experimental study has been conducted by Schabacker and Bölcs (1996) to quantify the uncertainty of the presented PIV measurements. Typically, 50 field samples were ensemble averaged on each measurement plane and for each phase angle. From these measurements it was determined that the $95 \%$ confidence interval for the mean velocity field is less than $0.08 \mathrm{~V}_{\infty}$, in regions of strong velocity gradients it is smaller than $0.1 \mathrm{~V}_{\infty}$. The determination of the position of the shock depends mainly on the maximum size of the interrogation window. Therefore, the position of the shock for instantaneous data sets can be determined with an error in the order of $0.5 \%$ of the chord length of the blade.

\section{RESULTS AND DISCUSSION OF THE FLOW}

\section{Steady-State Results}

In this section some characteristic steady-state results will be presented. In Figure 5 a typical example of an instantaneous velocity-vector map is depicted. The Mach number magnitude

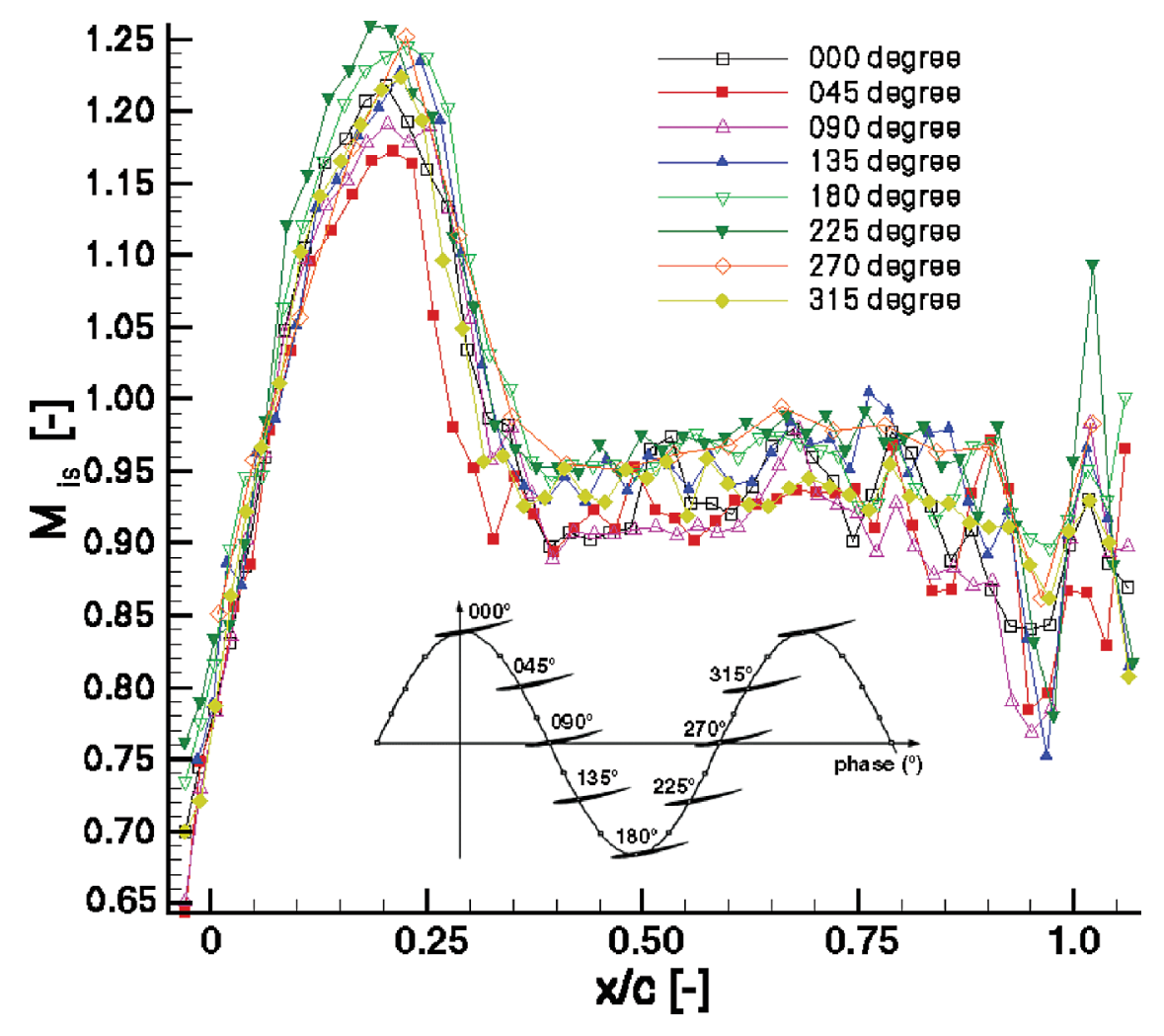

FIGURE 9

Isentropic Mach number distribution on the suction side of the vibrating blade at different phase angles, $M_{\infty}=0.65, f=20 \mathrm{~Hz}$. 
is color-coded and the vectors are instantaneous velocity disturbances $\mathrm{V}-\mathrm{V}_{\text {mean }}$ and represent in particular the final grid spacing obtained for all experiments that correspond to a spatial resolution in the flow field of approximately $0.5 \mathrm{~mm}$.

Attention should be paid to the white zone in the vector map. This is a region where no valid correlation can be obtained. It is in the proximity of the blade due to reflections, and at the leading and trailing edge, where due to the curvature of the blade the laser light arriving from the bottom is refracted and a shadowed zone occurs, where no particles are illuminated.

Although approximately $2.5 \%$ of all vectors were automatically detected as spurious by an in-house LabVIEW software, there still remain some obviously false vectors especially close to the blade (see Figure 5). These occur due to reflection problems in the proximity of the blade and have to be manually removed.
In order to validate the PIV method in the Unsteady Wind Tunnel, steady-state results have been compared to pressure taps measurements on the blade surface (Nowinski, 1999) and to calculations with the INST code (Ott, 1992) (see Figure 6). The INST code is based on the conservative form of the twodimensional, time-dependent Euler equations.

Even though the PIV data set for Figure 6 has been extracted from streamlines near (approximately $5 \mathrm{~mm}$ ) to the blade surface, the PIV results are in good agreement with both pressure taps measurements and INST calculations. However, some specific details can be observed, especially on the suction side where the flow strongly accelerates up to about $25 \%$ of chord followed by a strong normal shock. Due to boundary layer effects in the pressure taps measurements, the shock location on the suction side of the blade is completely smeared. On the other hand, the

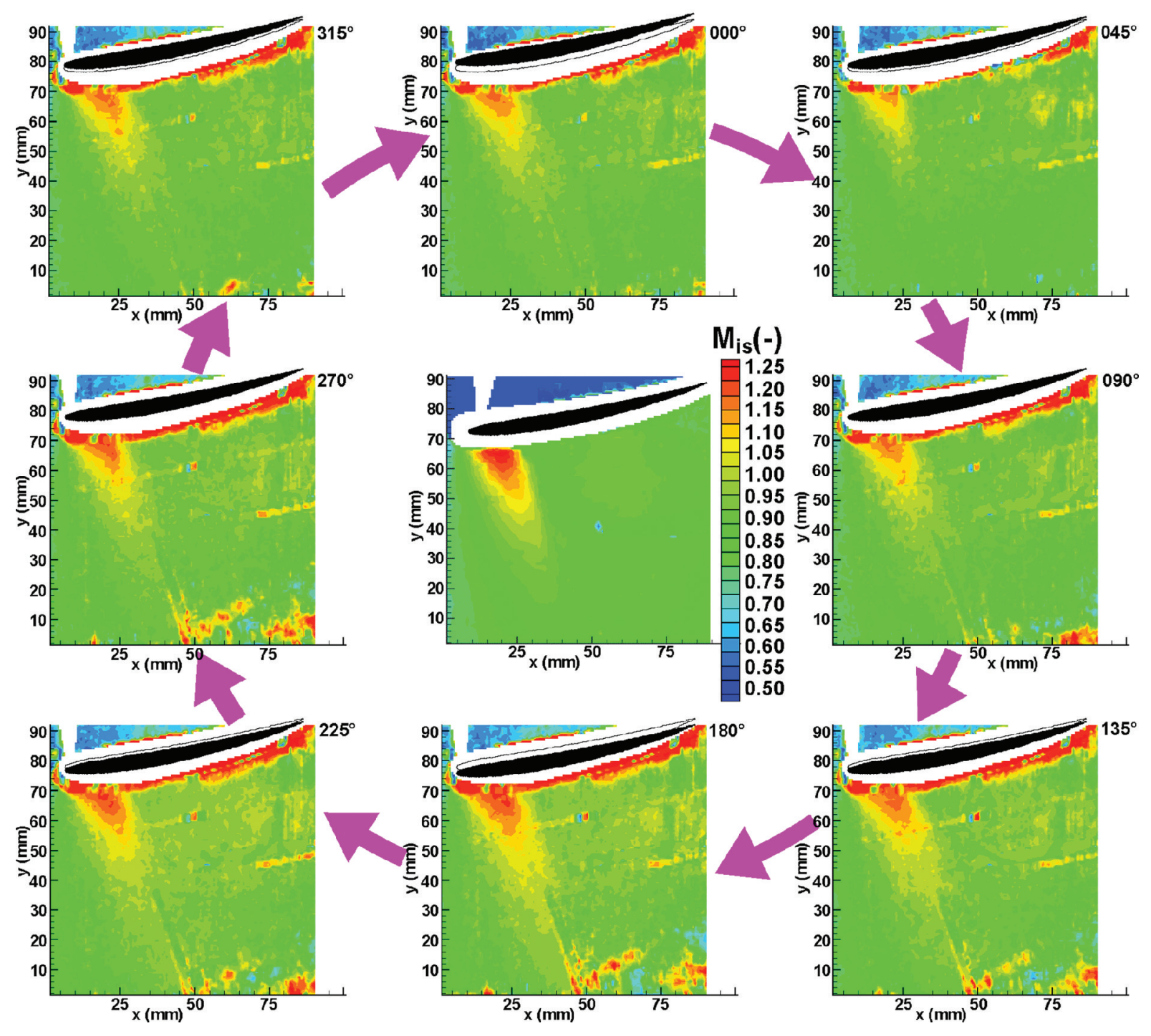

FIGURE 10

Time-variant flow field around the vibrating blade at different phase angles, $f=20 \mathrm{~Hz}, M_{\infty}=0.65$, steady-state flow field in the center. 
PIV results clearly reveal the supersonic flow region. However, the position of the shock is also smeared. Since the shock is very sharply determined in the instantaneous recordings (Figure 5), this smearing effect is due only to the ensemble-averaging of the individual data sets. The steady-state results are explained in more detail by Lehr and Bölcs (2000).

The isentropic Mach number distribution of the PIV measurements in Figure 6 also highlights the gap of values on the pressure side above the leading and trailing edge of the blade due to the shadowed zones in the flow field.

\section{Unsteady Results}

To obtain the results shown in this section, for each phase angle frequency case, 50 individual instantaneous data sets are ensemble averaged. For all results shown in this section the inlet Mach number is $M_{\infty}=0.65$, the excitation frequency for the gust generation, the blade vibration and the combination of both is fixed to $f=20 \mathrm{~Hz}$.

\section{Phase-Averaged Results with Gust Perturbation}

Figure 7 represents the isentropic Mach number distribution for one complete cycle of the gust generator in steps of $\Delta \varphi=45^{\circ}$ for the phase angle (see explanation in the lower right corner of Figure 7). One can observe that the region in which supersonic flow occurs considerably changes. The location of the strong normal shock terminating this region varies between $25 \%$ of chord for $\varphi=45^{\circ}$ and $85 \%$ for a phase angle of $\varphi=225^{\circ}$. This implies harsh changes in the aerodynamic loading of the blade and there exists a phase shift of approximately $\Phi=45^{\circ}$ between the excitation source and the aerodynamic response of the flow. However, the resolution of discrete angles $\varphi$ at which PIV measurements are conducted is not high enough to determine more precisely the phase angle $\Phi$.

The flow field information for the same cycle of the gust generator can be seen in Figure 8 at the border - the steadystate ensemble averaged flow field for the same flow conditions $\left(M_{\infty}=0.65, i=5^{\circ}\right)$ in the center.

These phase-averaged data of the flow field at several time instants over one excitation cycle clearly show the important fluctuations of the flow over the whole test section. For phase angles of $180^{\circ}<\varphi<270^{\circ}$, the supersonic flow region almost reaches down to the lower wall of the test section.

\section{Phase Averaged Results with Blade Vibration}

Figure 9 represents the isentropic Mach number distribution for one complete cycle of the vibrating blade in steps of $\Delta \varphi=$ $45^{\circ}$ for the phase angle.

Two main aerodynamic differences can be observed with respect to the unsteady results with back pressure variation. Firstly, the variations of the flow field created by the blade vibration are as expected (Nowinski, 1999) significantly less important. Nevertheless, the maximum Mach number varies over one complete

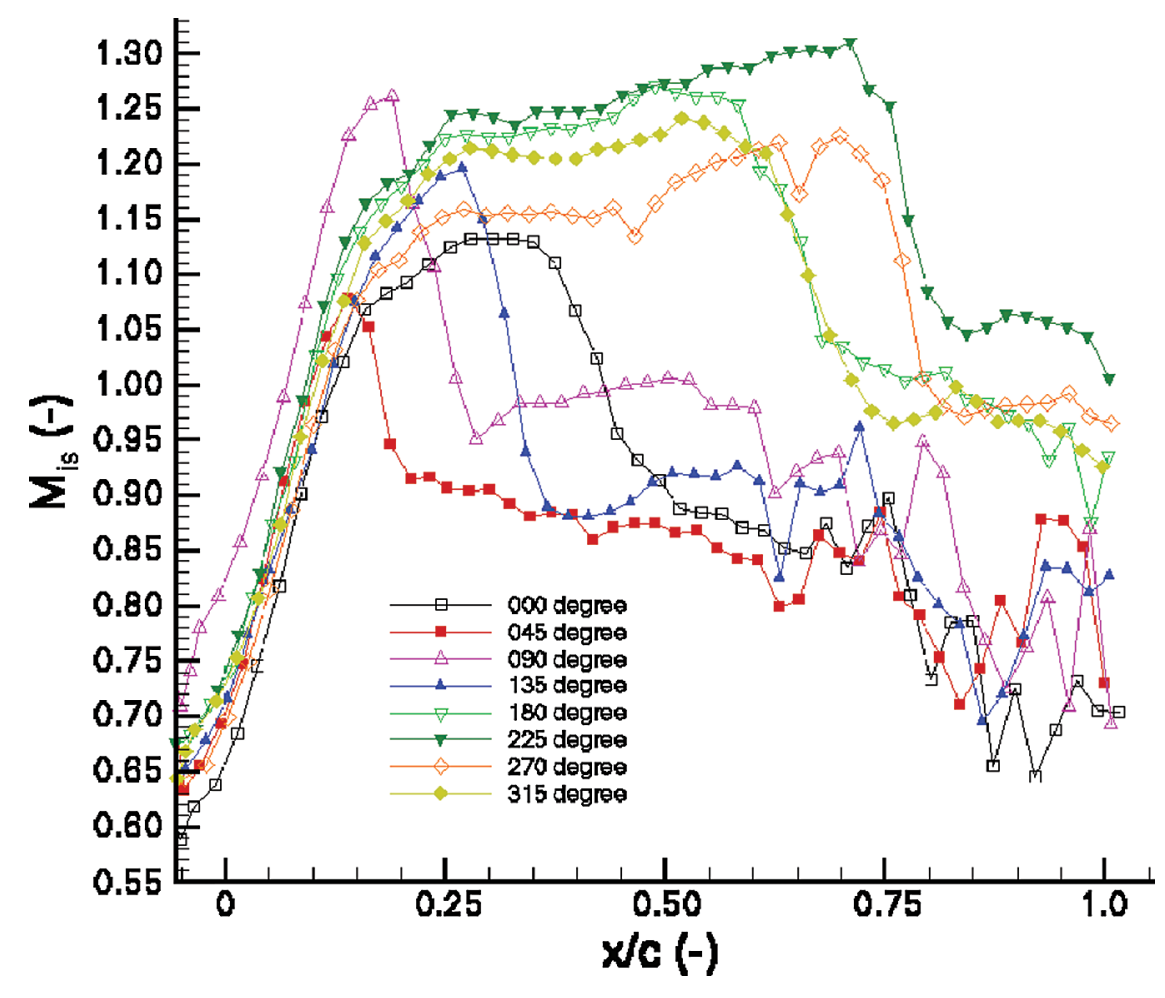

FIGURE 11

Isentropic Mach number distribution on the suction side of the vibrating blade with gust generation at different phase angles, $M_{\infty}=0.65, f=20 \mathrm{~Hz}, \mathrm{PPA}=0^{\circ}$. 
cycle of the blade vibration between $1.15<M_{\max }<1.27$ with a phase shift of approximately $\Phi=45^{\circ}$ (Figure 9). Secondly, the position of the shock remains approximately constant over the whole cycle, i.e. at $25 \%$ of chord. This corresponds to the steadystate shock position (Figure 10, center). In all cases, boundary layer separation occurs from $85 \%$ of chord (Figure 9).

Additionally, the noise level in the results with blade vibration increases significantly. Due to this effect, strong oscillations occur in the Mach number distribution close to the blade for $x / c>0.50$ (Figure 9). Furthermore, mainly due to additional reflections, the noise level increases over the whole flow field (Figure 10). On one hand, these additional reflections originate in a tiny maladjustment due to the blade vibration itself. Due to the blade motion itself, there are less particles in the proximity of the blade. At the same time, the blade motion causes a stronger contamination of the blade surface with par- ticles, which also increases the reflections in proximity to the blade surface. These two effects result in less valid correlations and therefore in a higher noise level close to the blade surface (Figure 10). On the other hand, since the blade is made of Plexiglas, it is slightly flexible. Hence, the vibration of the blade is not a pure plunging motion, it is rather superimposed by a bending component. To reduce this bending component, the blade is stiffened with tempered adjust pins. However, the bending component cannot be completely avoided. Therefore, a higher level of reflections can be observed over the whole flow field (Figure 10). Since the test section is not very large in proportion to the height, this effect is even amplified by the sidewall reflections.

\section{Gust Perturbation and Blade Vibration}

Finally, both effects are superimposed. Figure 11 represents the isentropic Mach number distribution for one complete cycle
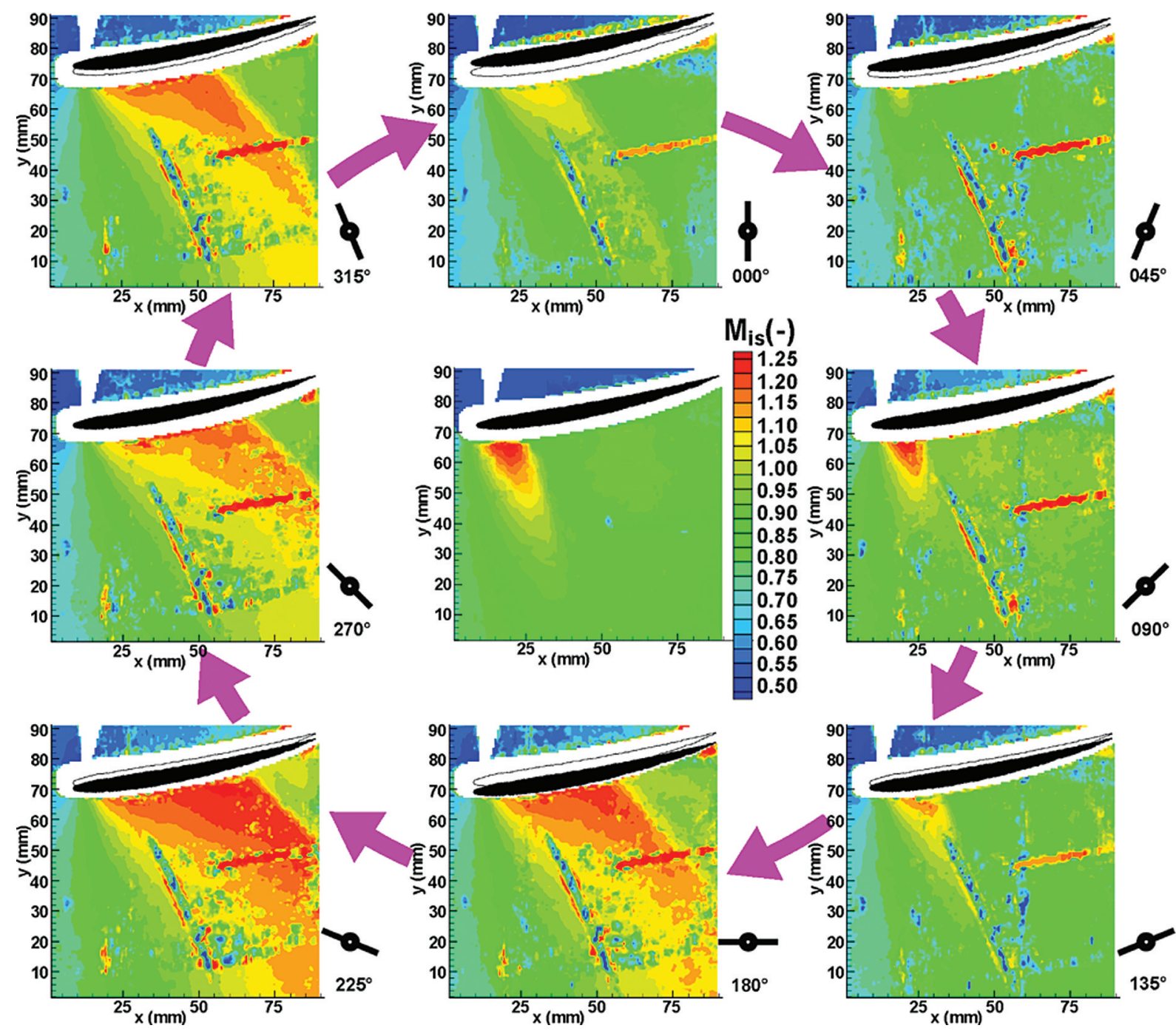

FIGURE 12

Time-variant flow field around the vibrating blade with gust generation at different phase angles, $f=20 \mathrm{~Hz}, M_{\infty}=0.65, \mathrm{PPA}=$ $0^{\circ}$, steady-state flow field in the center. 
of the vibrating blade in the presence of back pressure variations (gust perturbation) in steps of $\Delta \varphi=45^{\circ}$ for the phase angle. Since both gust perturbation and blade vibration separately have an offset of about $45^{\circ}$, the angle between phase angle of gust generator and vibrating blade Perturbation Phase Angle (PPA) is set to zero degrees.

It is obvious that the influence of the backpressure variation significantly dominates the aerodynamic effect of the vibrating blade. The blade undergoes a drastic change of aerodynamic loading. The shock position varies between $20 \%$ of chord slightly supersonic at $\varphi=45^{\circ}$ up to $80 \%$ of chord with $M_{\max }=1.3$ at $\varphi=225^{\circ}$. For phase angles of $180^{\circ}<\varphi<315^{\circ}$, the supersonic flow region almost reaches down to the lower wall of the test section.

In the same way as described above, the blade vibration creates additional reflections, which can be recognized from $60 \%$ of chord in Figure 11 and over the whole flow field in Figure 12. For measurements with both blade vibration and gust perturbation these reflections are due to the superposition of both effects particularly pronounced. However, the reflections are restricted to two narrow bands in the flow field, induced by the lens effect of the leading edge and the reflection of it at the lower wind tunnel wall. All other regions of the flow field are not affected and therefore yield very good quantitative results.

One can see from Figure 11 that the boundary layer separates for phase angles in a range of $0^{\circ}<\varphi<135^{\circ}$ at approximately $80 \%$ of chord. The boundary layer remains attached for phase angles of $180^{\circ}<\varphi<315^{\circ}$ due to a strong acceleration on the suction side of the blade.

Furthermore, one can observe that the aerodynamic response of the superimposed excitations has a phase shift of $\Phi=90^{\circ}$, although the phase shift of each single excitation is approximately $\Phi=45^{\circ}$. However, as already seen above, the resolution of discrete angles $\varphi$ at which PIV measurements are conducted is only $\Delta \phi=45^{\circ}$. Hence, it is not good enough to determine more precisely the angle of the phase shift $\Phi$. Nevertheless, it can be concluded that the superposition of both blade vibration and gust perturbation with a phase shift of $\Phi=45^{\circ}$ tend to influence the phase angle $\Phi$ between excitation source and aerodynamic response.

\section{CONCLUSIONS}

As already shown in previous papers (Lehr and Bölcs, 2000), PIV is well suited to revealing instantaneous flow field information in the Unsteady Wind Tunnel. With this PIV measurement technique it is possible to gather instantaneous flow field information across planes in the test section, both under steady-state conditions and in the presence of oscillating perturbations. Averaging of a high number of data sets yields quasi-steady velocity information over a large flow field with a very good quality and high spatial resolution. When applied to the unsteady measurements, the phase-averaged results allow for a quantitative insight into the flow field behavior under strong and rapid aerodynamic variations.
The objective of the tests presented in this article was to apply the PIV method to the unsteady flow field due to (1) downstream created pressure perturbations introduced by a gust generator, (2) an isolated compressor airfoil put to plunging mode vibration, and (3) a superposition of (1) and (2). Some fundamental knowledge on the flow behavior of these unsteady state flow fields can be deduced from these PIV measurements:

- The flow field sustains strong variations in the presence of downstream created pressure perturbations introduced by a gust generator. Likewise, the vibrating blade forces the flow field to vary periodically. However, the variations provoked by the pressure perturbations largely dominate the blade vibration induced unsteadiness of the flow.

- The unsteady measurements reveal a phase angle of $\Phi \approx 45^{\circ}$ between the excitation source and the aerodynamic response for both cases (1) gust perturbation and (2) blade vibration. However, when (1) and (2) are superimposed at a perturbation phase angle PPA $=0^{\circ}$, the phase angle shifts to $\Phi \approx 90^{\circ}$. This phenomenon was observed for all measurements conducted within the scope of this work.

- Since the PIV method only takes snapshots of the flow field at discrete instants, i.e., discrete angular positions $\varphi$ of the excitation cycle, the resolution of $\varphi$ of the results presented in this work is not good enough. Hence, more discrete angular positions $\varphi$ have to be taken into account in order to determine more precisely the phase angle $\Phi$.

\section{FUTURE WORK}

The results presented in this article summarize a project on the practical application of a PIV system in an Unsteady Wind Tunnel. Due to constructional constraints of the present apparatus, some work will be undertaken to ensure the sinusoidal plunging motion of the blade by redesigning the test section, i.e., adapting the test section to a different blade geometry and modifying the hydraulic vibration system. Furthermore, the research will focus on minimizing the reflections within the test section and their subsequent effects. This will be achieved by advanced numerical post-processing procedures and direct endoscopic introduction of the laser light sheet.

Continuing experiments will concentrate on investigating the flow field in the test section around the vibrating blade with backpressure variation (gust generation). A wider range of reduced frequencies, a better resolution of phase angles, and the behavior for different perturbation phase angles PPA will therefore be investigated.

In addition, measurements with fast-response aerodynamic probes $\left(\right.$ FRAP ${ }^{\circledR}$ ) are planned to validate the two measurement techniques using different physical principles and enhance the experience with FRAP ${ }^{\circledR}$ probes in unsteady transonic flows. These measurements are conducted in collaboration with the 
Swiss Federal Institute of Technology, LSM-ETH, in Zurich, Switzerland.

\section{NOMENCLATURE}

$c \quad[\mathrm{~m}]$ chord length of the blade

F-number [-] chord length of the blade

$f \quad[\mathrm{~mm}]$ focal length

$f \quad[\mathrm{~Hz}]$ excitation frequency

F-number [-] relative aperture of the camera lens

$i \quad\left[{ }^{\circ}\right]$ incidence angle

$k \quad[-]$ reduced frequency, $f \pi c / U_{1}$

$M \quad[-]$ Mach number

PPA $\quad\left[{ }^{\circ}\right]$ perturbation phase angle (angle between phase angle of gust generator and vibrating blade)

Re [-] Reynolds number based on chord length, $U_{1} c / v_{1}$

$T \quad[\mathrm{~K}]$ temperature

$(u, v, w) \quad[\mathrm{m} / \mathrm{s}]$ velocity vector

$V \quad[\mathrm{~m} / \mathrm{s}]$ velocity in the measurement plane, $V=$ $\sqrt{u^{2}+v^{2}}$

$x \quad[\mathrm{~mm}]$ Cartesian coordinate in axial direction

$y \quad[\mathrm{~mm}]$ Cartesian coordinate in cross duct direction

$z \quad[\mathrm{~mm}]$ Cartesian coordinate in span direction

$\varphi \quad\left[{ }^{\circ}\right]$ phase angle of the rotating blade (gust generator)

$v \quad\left[\mathrm{~m}^{2} / \mathrm{s}\right]$ kinematic viscosity

$\Phi \quad\left[{ }^{\circ}\right]$ phase angle between excitation source and aerodynamic response

\section{Subscripts}

$1, \infty \quad$ condition upstream of the blade

mean mean value averaged over the whole flow field

PS pressure side of the blade

SS suction side of the blade

$T \quad$ stagnation condition

\section{REFERENCES}

Adrian, R. J. 1991. Particle-imaging techniques for experimental fluid mechanics. Annual. Rev. Fluid Mech 23:261-304.

Bölcs, A., and Norryd, M. 1994. Development of a sealing construction to prevent leakage flow during flutter tests in a linear cascade. 12th Symposium on Measuring Techniques for Transonic and Supersonic Flow in Cascades and Turbomachines, Prague, 12-13 September.

Bryanston-Cross, P. J. 1995. The application of PIV (particle image velocimetry) to transonic flow measurements. $\mathrm{CH} 34827-95 / 0000$ 53.1, IEEE 1995.

Bryanston-Cross, Towers, P. J., Judges, C. E., and Harasgama, D. P. 1991. The application of particle image velocimetry in a short duration transonic annular turbine cascade. ASME Paper 91-GT-221.

Fleeter, S., and Jay, R. L. 1987. Unsteady aerodynamic measurements in flutter research. AGARD Manual on Aeroelasticity in Axial-Flow Turbomachines, AGARD-AG-298, Volume 1.

Grant, I., (Ed.). 1994. selected papers on particle image velocimetry. SPIE Milestone Series, Vol. MS 99.
Grant, I., Pan X., Wang X., and Stewart, N. 1994. Correction for viewing angle applied to PIV data obtained in aerodynamic blade vortex interaction studies. Experiments in Fluids 18, City: Springer-Verlag, 95-99.

Höcker, R. 1990. Untersuchung der Transsonischen Umströmung eines stumpfen Zylinders mit Hilfe der Geschwindigkeitsfeldmeßmethode, dissertation, Georg-August-Universität zu Göttingen.

Kompenhans, J., and Höcker R. 1988. Application of particle image velocimetry to high speed flows. Particle Image Displacement Velocimetry, von Karman Institute for Fluid Dynamics, 67-84.

Kompenhans, J., Raffel, M., Wernert, P., and Schäfer, H. J. 1994. Instantaneous flow field measurements on pitching airfoils by means of particle image velocimetry. Optical Methods and Data Processing in Heat and Fluid Flow, London, 14-15 April.

Langowski, C., and Voigt, P. 1994. Film cooling of an annular turbine stator visualisation of cooling air ejection and its effect on the aerodynamic losses. 12th Symposium on Measuring Techniques for Transonic and Supersonic Flow in Cascades and Turbomachines, Paper 19, Prague, Czech. Rep., September 12-13.

Lehr, A., and Bölcs, A. 2000. Application of a Particle Image Velocimetry (PIV) System to the Periodic Unsteady Flow Around an Isolated Compressor Blade, paper presented at the 15th Bi-annual Symposium on Measurement Techniques in Transonic and Supersonic Flow in Cascades and Turbomachines, University of Florence, 21-22 September.

Liu, Z.-C., Landreth, C. C., Adrian, R. J., and Hanratty, T. J. 1991. High resolution measurement of turbulent structure in a channel with particle image velocimetry. Experiments in Fluids 10:301-312.

Nowinski, M. 1999. Experimental Investigation of an Oscillating Airfoil in the Presence of Downstream-Generated Aerodynamic Gusts. Thèse No. 2072 (1999), EPFL, Lausanne.

Ott, P. 1992. Oszillierender senkrechter Verdichtungsstoß in einer ebenen Düse, Communication du Laboratoire de Thermique Appliquée et de Turbomachines de l'Ecole Polytechnique Fédérale de Lausanne, No. 18.

Raffel, M., Willert, C., and Kompenhans, J. 1998. Particle image velocimetry, a practical guide. City: Springer-Verlag.

Schabacker, J., and Bölcs, A. 1996. Investigation of turbulent flow by means of the PIV method, paper presented at the 13th Symposium on Measuring Techniques for Transonic and Supersonic Flows in Cascades and Turbomachines, Zurich, Switzerland, 5-6 September.

Tisserant, D., and Breugelmans, F. A. E. 1995. Rotor blade-to-blade measurements using particle image velocimetry. ASME, 95-GT-99.

Towers, C. E., Bryanston-Cross, P. J., and Judge, T. R. 1991. Application of particle image velocimetry to large-scale transonic wind tunnels. Optics \& Laser Technology 23(5):289-295.

Visser, F. C., and Jonker, J. B. 1995. Investigation of the relative flow in low specific speed model centrifugal pump impellers using sweepbeam PIV. Flow Visualization VII, Begell House Publishers, ISBN 1-56700-036-3, 1995.

Wernert, P., Koerber, G., Wietrich, F., Raffel, M., and Kompenhans, J. 1995. PIV measurements and laser-sheet visualization of the unsteady flowfield over an airfoil pitching in dynamic stall conditions. Flow Visualization VII, Begell House Publishers, ISBN 1-56700036-3, 1995.

Willert, C., Stasicki, B., Raffel, M., and Kompenhans, J. 1995. A digital video camera for application of particle image velocimetry in highspeed flows. SPIE Proceedings Article No. 2546-2519. 

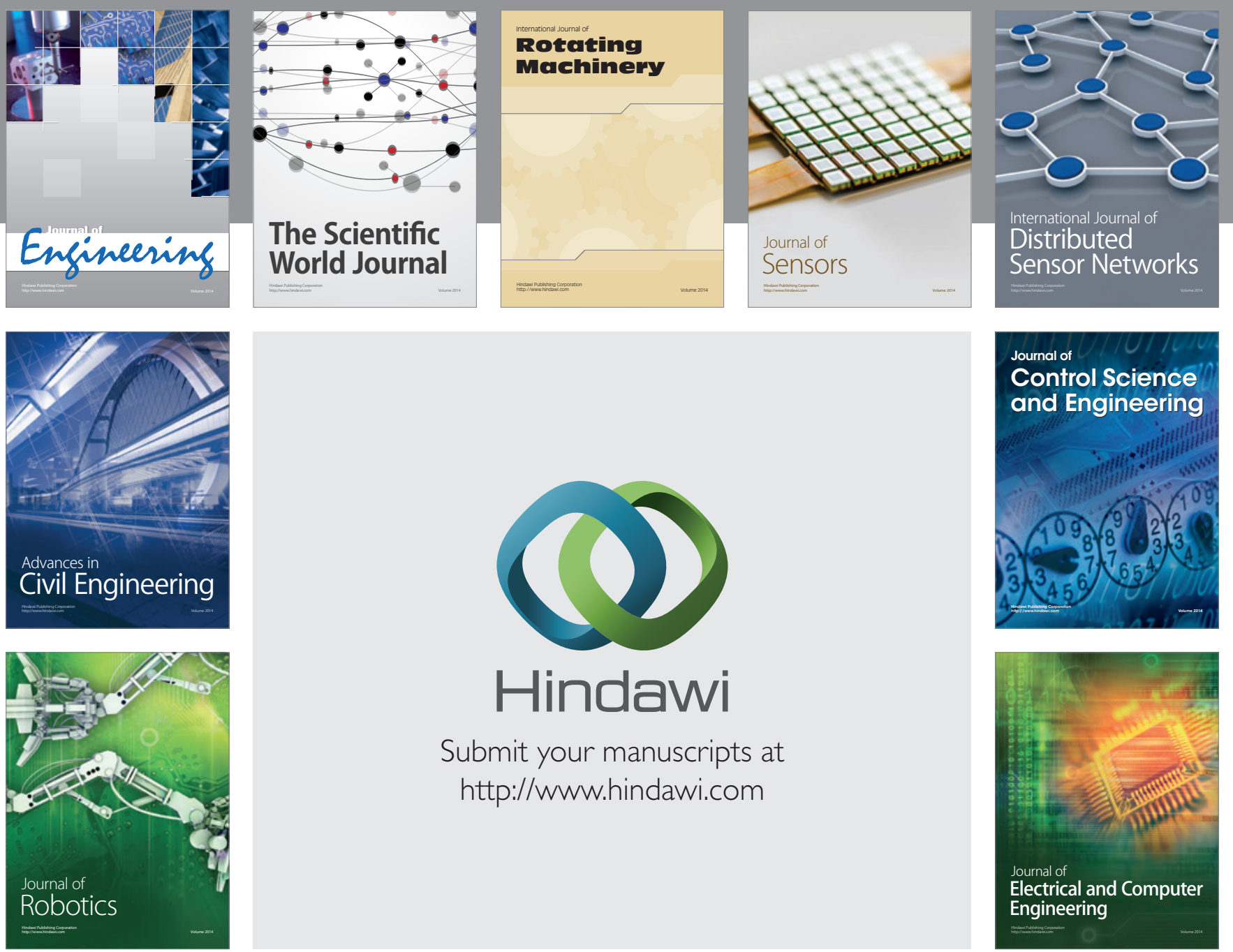

Submit your manuscripts at

http://www.hindawi.com
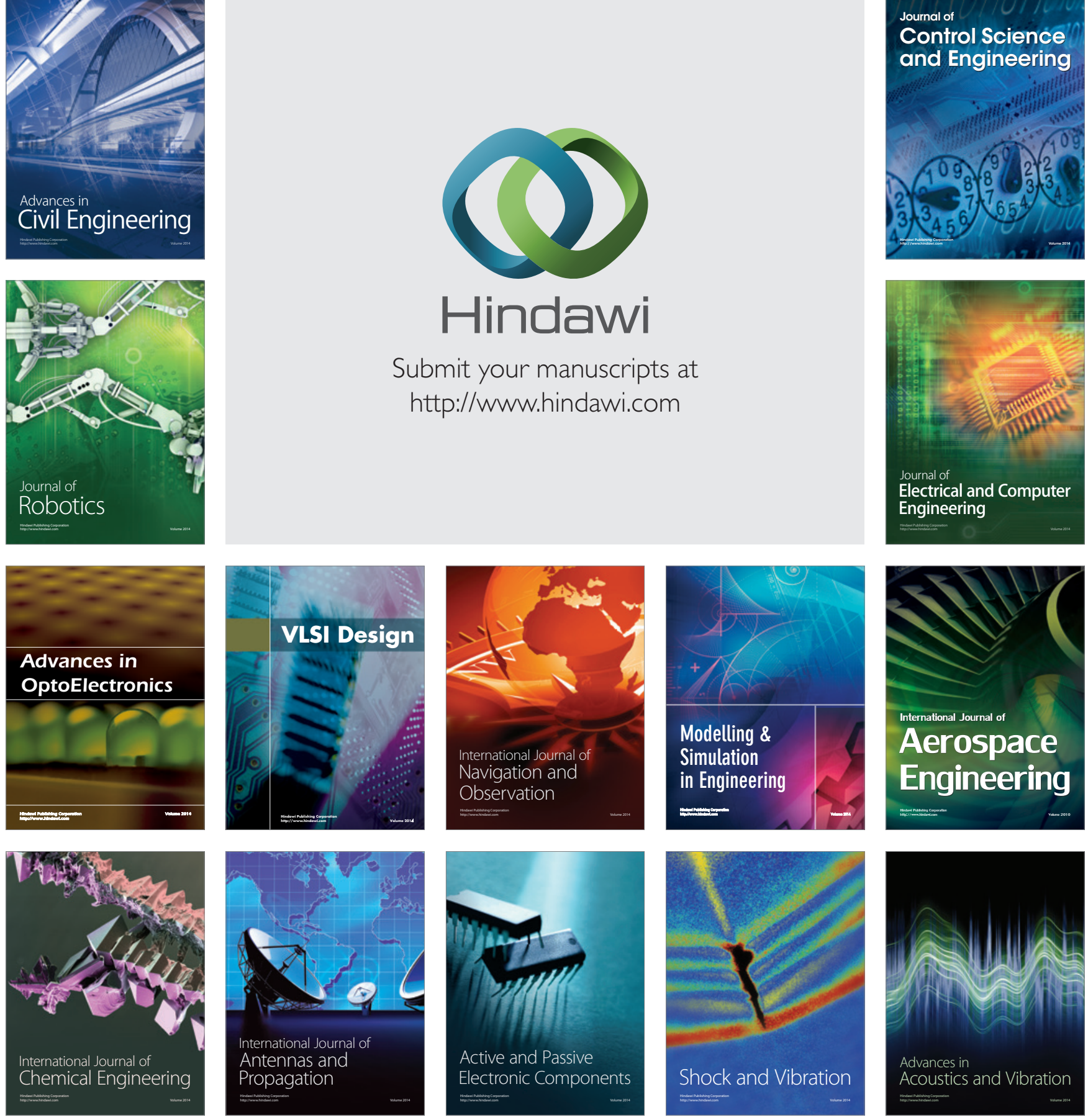